\title{
Introduction: Human Ecology in the Himalaya
}

\author{
Thomas Fricke $^{1}$
}

Knowledge of human adaptation in the Himalayas has developed more slowly than that for other world mountain systems. At the same time, the opening of the region to research has focused attention toward description in a "natural history" mode until quite recently. Where these studies have addressed issues of adaptation they have tended to do so more as a heuristic tool rather than in terms of contributing to the development of adaptive perspectives from a uniquely Himalayan vantage point. The contributions to this special issue suggest some of Himalayan cultural ecology's new themes as it more directly assumes a truly processual approach that incorporates the individual and domestic dimensions of adaptation within historical and social contexts.

KEY WORDS: Himalaya; process; mountain adaptation; history.

It is true that our knowledge of the large portion of these mountains, lying beyond the limits of British dominion, is far from complete. But is our knowledge anything like complete in our own hill possessions? And, if we are to wait until Nepal, Sikkim, and Bhutan become thoroughly accessible to science, must we not indefinitely postpone a work, the most material part of which may (I think) be performed with such information as we now possess? (Hodgson, 1874, p. 1).

The ecological study of highland populations of Nepal in terms of their unique cultural adaptations to a multizoned Himalayan environment is in its infancy (Messerschmidt, 1976, p. 167).

${ }^{1}$ Institute for Social Research, Department of Anthropology, The University of Michigan, Ann Arbor, Michigan 48106. 


\section{INTRODUCTION}

Linguistic traces of the Raj aside, Brian Hodgson's preface to his 1849 description of Himalayan physical geography carries echoes over 100 years later in an article by Don Messerschmidt which appeared in this journal. Together, the two quotes illustrate the halting advance of ecological knowledge in the Himalaya where even our basic knowledge of people and cultures lagged far behind that of other mountainous areas. In spite of the efforts of Hodgson and others toward fleshing out the physical and social contours, descriptions of the Himalayan region were to remain general or unduly schematic for another 80 years. Much of what was written applied to the major transit ways through the mountains and the few large valleys within them. Information for other areas was often confined to little more than the listings of "tribes," crops, and domestic animals that litter the British consul reports.

S. D. Pant's (1935) now classic study of Almora District in India marked the first systematic description of a Himalayan economic adaptation. Published a year before Peattie's (1936) similarly empirical study of European mountain geography, Pant's work established the foundation for what is known about Himalayan agropastoralism, the significance of trade, and even the role of women in the Hindu-dominated regions to the west of Nepal. But this well-grounded beginning was not to be followed for another 30 years when scholars began to document the social, cultural, and economic diversity of the Himalayan region in a series of community and subregional studies that suddenly became available in the 1960s (Berreman, 1972; FürerHaimendorf, 1964; Hitchcock, 1966; Madan, 1965; McDougal, 1968). ${ }^{2}$

These early modern efforts concentrated on filling out the ethnographic map of Nepal and other parts of the Himalaya (Bista, 1967) and seldom explicitly addressed cultural ecological issues, ${ }^{3}$ although some of them were motivated by fully fleshed-out theories of human and environmental interactions. A striking example of this was John Hitchcock's attempt to apply the Stewardian method of cultural ecology to the effect of altitudinal zonation on cultural variation among the Magar of Nepal (described in Hitchcock, 1980, pp. 135-137; Hitchcock, 1973). Barth's (1956) description of the relations of ethnic groups in Swat in terms of ecological niches similarly stands

\footnotetext{
${ }^{2}$ Interested readers should consult the excellent review by Fisher (1985) and be aware, of course, that there were important exceptions to the bleak ethnographic picture-just painted. Gorer's (1938) work with the Lepcha of Sikkim is one of these.

${ }^{3}$ Andress's (1966) dissertation in geography was an exception along with a dissertation by Nitzberg (1970). Other regional examinations from geography that touched at least descriptively on ecological themes include the efforts of Hagen (1961). For the most part, however, setting and economy were discussed as parts of more general ethnographic descriptions.
} 
out as an early human ecological effort. In general, however, the research phase in the Himalaya beginning with the early 1950's and lasting until roughly 1970 can be thought of as a "natural history" period followed by a more developed adaptive orientation.

As with the application of other theoretical models to the study of Himalayan societies (Ortner, 1978), the 1970's and 1980's marked the fruition of ecological themes. Often based on work initiated in the prior decade, a series of articles began to describe and analyze productive strategies in terms of their impact on the environment (Hitchcock, 1977; Hoffpauir, 1978; Calkins, 1981) or in a vocabulary that integrated description with a concern for adaptive processes (Alirol, 1976; Messerschmidt, 1974). Where cultural ecological studies have generally developed through three roughly defined historical phases culminating in an emphasis on process (Orlove, 1980), the ecological work in the Himalaya resists neat chronological ordering. Elements of Stewardian cultural ecology (Hitchcock, 1973, 1977) appear simultaneously with more processually-oriented analyses (Goldstein, 1977). But where Himalayan research has made occasional use of theoretical concepts embodied in processual cultural ecology, its orientation has been largely toward their heuristic use rather than toward their development. In fact, a distinguishing characteristic of ecological studies in the region is the tendency until recently to focus on empirical issues or problems related to environmental degradation rather than more general contributions to theories of adaptation (Hoffpauir, 1978; Macfarlane, 1976; Goldstein, 1976; Dahal, 1983; Fricke, 1986).

The general contours of mountain adaptation are by now well known thanks to the comparative syntheses of the last 15 years, to which Himalayan studies have contributed (Rhoades and Thompson, 1975; Brush, 1976; Guillet, 1983). Mountain environments present overwhelmingly structured restrictions and opportunities to human adaptation, and these are largely determined by the vertical zonation of micro-environments. ${ }^{4}$ At a gross level, the solutions to these problems of production have been achieved in remarkably parallel ways across mountain regions of the world. Mixed mountain agriculture matching varieties of grain with appropriate altitude and the planting of root crops in the upper elevations, agropastoral transhumance, fragmentation of household landholdings, and various strategies mixing community control of resources with family ownership are among the widespread strate-

\footnotetext{
${ }^{4}$ The scientifically inclined Hodgson early on suggested ranges for the Himalayan zones: "...I have assigned 4000 feet of elevation as the southern limit of the healthful and temperate midregion; that above it being the arctic or boreal, and that below it, the tropical region, though it must never be forgotten that much of the tropical characters, especially in the course of the seasons, pervades the whole breadth (and length likewise) of the Himalaya..." (Hodgson, 1874, p. 22). John Metz's article in this issue of Human Ecology represents a continuation and refinement of this effort.
} 
gies employed by mountain people to gain a livelihood from local environments. At the same time, locally scarce resources have been obtained through different styles of contact with neighboring communities involving longdistance trade and seasonal movement of whole communities.

Ecological studies from the Himalaya generally confirm this broad typological picture. The verticality of natural eco-zones and overlapping zones of production are well established as are the general features and timing of transhumant cycles that take advantage of seasonal changes within zones (Messerschmidt, 1974; Alirol, 1976). Partible inheritance strategies and the advantages of fragmented landholdings at the household level characterize much of the Himalayan landscape (Levine, 1988; Fricke, 1986; Macfarlane, 1976) in ways that parallel European strategies (Netting, 1981). Larger historical trends have also shown parallels across regions, as in the increasing reorientation of highland peoples toward lowland populations as a result of twin pressures of population growth and political developments (Brush, 1976; Messerschmidt, 1976).

In many ways, Himalayan research has come of age. The thin detail of the ethnographic map confronting Hodgson and the anthropologists and geographers of the 1950's and 1960's is rapidly filling and much of what is new involves making general models of mountain adaptation more specific to the Himalaya.

Until recently, the typology of subsistence types in Nepal has more or less borrowed the notion of verticality from the general literature on mountain adaptations; the encompassing term "agropastoral" has been similarly used as a catchall to describe the subsistence activities of peoples living in environments as diverse as the semi-arid northwestern parts of Nepal to the slopes immediately around the city of Kathmandu. Such general terms applied to comparisons of populations within the Himalaya impede appropriate analysis by obscuring the real and important variations characterizing subsistence orientations. As Metz points out in this issue, a person familiar with the full range of Himalayan subsistence possibilities would be unlikely to generalize from, for example, Fisher's description of adaptation in Tarangpur (1986) to discuss subsistence activities in Ilam District described by Dahal (1983). On the other hand, generalizations about economic and fertility patterns have been made on the basis of common ethnicity in Nepal, as, for example, between Tamang villages. Yet, a look at Table IV in the Metz article demonstrates the extent to which subsistence and ethnicity may be separate dimensions. Depending on the questions one has in mind, more appropriate generalizations may be made about the Tamang village of Timling $(26)^{5}$ from

${ }^{5}$ Numbers in parentheses throughout this introductory essay refer to the numbers assigned to villages in Metz's Table IV. 
information gathered in Siklis (12), a Gurung village, than from the Tamang village of Manigaon (15). ${ }^{6}$

While the classification that Metz proposes represents a refinement of more straightforward altitudinal classifications for the Himalaya, it contains restrictions that he is aware of. For one, it assumes the predominance of locally-derived subsistence in most villages. While this is a condition that continues to be largely true for the Nepal Himalaya, it is rapidly changing even here as wage labor opportunities and market goods find their way into even remote settlements. For example, preliminary analyses of data gathered in Timling in 1987 indicate that $57 \%$ of all people in the village 12 years old and over have participated in road construction for wages. Even before these opportunities for wage labor, a substantial percentage of men $(21 \%)$ had been involved in marketing herbs from the high pastures in the bazaar town of Trisuli a few days walk from the village. This suggests that the Metz classification scheme represents a useful baseline for classifying populations, especially those for which descriptions have already been provided, but it does not obviate Allan's (1986) caveat that accessibility to markets and wage labor opportunities will play an increasingly greater role in production systems in mountainous areas. Even in Nepal with its still incipient system, the location of roads throughout the country has shaved days, often weeks, from the transit time to Kathmandu and other market centers. In the same way, new airstrips in remote locations have drawn these areas to within a few hours of influence from and access to the capital. To his credit, Metz is aware of the historical and ethnic processes that modify subsistence orientations within his categories. Moreover, the system he suggests nicely organizes past studies for real comparative analyses of social change in the Himalaya.

That the production activates are changing toward greater complexity in areas that the Metz scheme would probably align to either an upper- or high-elevation production system is indicated by Naomi Bishop's contribution. Bishop focuses on transformations within the village and pasture environs of Melemchi, a community in the Helambu region north of Kathmandu. Although she is specifically concerned with the move from a strategy of yakhybrid herding to one of yak-hybrid production for sale, the conditions within which this change is occurring describe the more general transformation occurring throughout the Himalaya. Messerschmidt's (1976) early discussion of historical movements by the Gurung from a high-altitude pastoral orientation to increasing reliance on lower-elevation agriculture is placed in a contemporary perspective by the description of trends in Melemchi. The

${ }^{6}$ This is not to say that important research questions cannot be asked based on the subsistence differences between villages of common ethnicity. The work of Hitchcock, already referred to, is an example of valid questions in this kind of framework. 
difference now is that the reorientation of mountain subsistence includes diversification in wage labor in addition to agricultural intensification (also see Sacherer, 1977). Moreover, Bishop's contribution demonstrates, I think, why the Metz scheme for subsistence types is appropriate for establishing a comparative baseline but needs to be used cautiously if our research questions have to do with process.

Consider the transformations in Melemchi. Since 1971, Bishop informs us, the number of houses in the village has doubled, there has been increasing movement between the village and wage labor activities in India, and increasing integration into Nepal's national infrastructure. In 1986, the year in which her current data was gathered, she depicts a village of 75 households in which 220 people (including those temporarily living in the pastures with their herds) were resident. Between 110-150 people have moved to India and are expected to remain there for varying lengths of time. When we consider that households as economic units in other settings tend to contain close to five members on the average (Macfarlane, 1976; Hoffpauir, 1978; Fricke, 1986), the transformation of Melemchi's available labor pool is all the more striking.

Bishop indicates that the people living in India behave quite autonomously relative to their families at home and that they live in India for varying lengths of time, sometimes permanently. While there are very likely remittances, the important point about this labor migration for her analysis and for its implications in other settings is its removal of labor from households at precisely the time in the developmental cycle when younger family members should be relieving their parents from the labor demands of yakhybrid herding. This tie-in with the familial mode of production and domestic developmental cycles is at least implicit throughout Bishop's discussion and suggests that research into changing Himalayan adaptations take stock of the intersection of life courses, family cycles, and the relationships among kin throughout their lives. ${ }^{7}$

Migration and remittance economies are not new in the Himalaya (Parry, 1979; Dahal, Manzardo, \& Rai, 1977; Toffin, 1976), but the context within which they occur differs considerably from region to region; the effects of labor migration depend on local social organization and the local subsistence economy in home villages as well as the form that the wage labor

${ }^{7}$ This is an increasingly important area of investigation in the demographic literature where John Caldwell's (1982) theoretical statements put the transformation in terms of wealth flows. In the Himalaya, the investigation into these and related issues has been initiated by the anthropologists at Case Western Reserve University (Goldstein and Beall, 1981; Goldstein, Schuler, and Ross, 1983). Other important treatments of related issues derive from the literature on gender and labor in the Himalaya (Sharma, 1980; Acharya and Bennett, 1981; Levine, 1981). 
jobs themselves take. ${ }^{8}$ Migration may be seasonally meshed with the annual subsistence cycle in which post-harvest slack times coincide with the peak availability of temporary portering jobs in the trekking industry. Or it may be meshed with the household developmental cycle when the microdemography of economic units permits labor diversification. Again, to refer to my own research, Tamang labor migration from Timling in the north central Nepalese Himalaya has long included movement to India in much the same way that Bishop suggests has been the case for Melemchi since the Second World War. While people may be gone from Timling for significant periods of time, there is general agreement that they may reclaim their inheritance upon their return regardless of the length of time away. In practice, the return from wage labor is expected to bring money into the local economy which should be turned over to fathers and likely invested in new land or cattle.

Bishop does not directly reflect on the continuing or anticipated relationships between household members who have relocated to India and those older members who have remained behind, although it is clear from her report that some of them are sending money back. This suggests that the study of Himalayan adaptations must become increasingly concerned with the new diversification of local household economies and the implications of the growing wage labor component within them. Bishop's excellent discussion draws our attention to the transformations in locally-available labor and its implications for production strategies at the household level. It also depicts the impact of these transformations on that group, senior household members, who may have been expected to benefit from the more local labor contributions of their children in the past.

The importance of evaluating labor contributions with respect to life course phases and the social organization of cooperation is illustrated by Catherine Panter-Brick's contribution to this volume. Based on remarkably detailed time allocation data from the village of Salme (number 27 on Table IV in Metz's discussion), Panter-Brick investigates the important question of the impact of pregnancy and childbirth on the contribution of women to the domestic economy in the Himalaya. Her contribution is best evaluated in the context of the watershed time allocation studies carried out by the Status of Women in Nepal Research Project in the 1970's (Acharya and Bennett, 1981) which demonstrated the substantial reliance of Himalayan production on women's labor inputs in agriculture across cultures. Panter-Brick's research indicates the power of statements based on quantitative individual-level data collection in Nepal, and demonstrates the value of multi-disciplinary team

'In addition to the cultural context. Ortner's (1989) new treatment of historical processes among the Sherpa suggests the complex interaction among cultural, economic, and political processes in one Himalayan setting. 
research for freeing researchers for intensive, specialized data collection. Her work was carried out as a part of an important French effort in Salme involving demographers, nutritionists, geographers, and anthropologists (Dobremez, 1986).

Earlier time allocation work in Nepal has demonstrated that women's work in the Himalaya is an essential component of the diversified household production strategies characteristic of mountain production in general. Moreover, the relative work efforts of men and women in primary production activities (animal husbandry, agriculture, wage-earning) appear to vary by ethnic group. Tibeto-Burmese villagers are more likely to approach genderequivalent contributions of time to these activities than are the Indo-Aryan villagers sampled in the Status of Women Study (Acharya and Bennett, 1981, p. 163; Molnar, 1981). While this indicates the significance of ethnicity and cultural tradition, another way to compare villages in that study is to place them in terms of their geography. ${ }^{9}$ Such a comparison indicates that women make the most substantial contributions to primary production in the environments demanding the most diversified household economic strategies, often freeing up male work time for the pastoral economy. Other results of that study indicate that the contributions of time to household production and the specific activities engaged in vary by age and relationship to household head.

Panter-Brick's analysis builds on this earlier work by asking the theoretically-important question of how individual life course events, childbirth in this case, affect the labor contribution of women. Her findings are that during the periods of greatest agricultural labor intensity in the mountain environment, spring and the monsoon period, there are no significant differences in the activities of pregnant and lactating women and those without young children. It is only during times of less intensive agricultural labor need and hence greater flexibility in time allocation that significant differences appear.

This analysis underscores the need to view the economic activities of individuals in terms of (1) cyclic processes (seasonality) defining general levels of activity and the need for labor, and (2) individual time defining the possible contribution of women within a given social context. Panter-Brick's finding that in the traditional hill economy centered on agropastoral pursuits, pregnant and lactating women are expected and, indeed, do perform the same tasks as non-lactating women suggests that it is not childcare itself which removes women from the productive economy of households undergoing the transition to wage labor (Fricke and Thornton, 1989). This is an

9Two of the villages from the Status of Women in Nepal Project appear in Table IV of Metz's discussion: Kagbeni (33) and Thabang (38). 
important finding made all the more compelling by its firm quantitative grounding. It raises questions about models of social change which assume that childbirth necessarily restricts the activities of women and suggests for development projects a rethinking of training programs that focus on men (March and Taqqu, 1986; Karan, this volume).

Where Panter-Brick's analysis focuses on individual and cyclic processes within a stable adaptation and Bishop documents a contemporary transformation, David Zurick demonstrates in his contribution that the adaptive village scenarios we find on our initial entry into the field are themselves the outcome of long-range historical sequences in which politics, ethnicity, and incremental internal transformations play an important role. In doing so, his contribution begins to tie the study of Himalayan adaptation yet more explicitly into the processual cultural ecological tradition in which adaptive strategies are themselves viewed as outcomes of a variety of interactions (Orlove, 1980; Orlove and Guillet, 1985).

Zurick focuses on the development of settlement patterns in a western Nepal village in terms of regional political economy and local history. In doing so, he provides an example of how studies of Himalayan adaptation can begin to incorporate the complex and lengthy histories of Himalayan state formation (English, 1985) and processes of ethnic interaction. Studies of adaptation in the Himalaya have often attempted to remove villages from the larger political currents and to presume an insular adaptation in which historical processes largely precipitated from the internal dynamics of population growth and land degradation (Fricke, 1986). Yet, by ignoring political economy in the past, we bias our interpretations of more recent change as, for example, when we assume that the differentiation of household strategies and wealth within villages represents the development of a class structure from an essentially egalitarian past.

While this may well be true in particular cases, our knowledge of historical ties between expanding state bureaucracies and local intermediaries suggests a much more complex picture. Thus, we know that local connections with the central Nepali government throughout the nineteenth century were organized in ways as various as quasi-feudal relationships with owners of land grants to less rigid systems stressing named village headmen responsible for collecting taxes (Regmi, 1978). The naming of these headmen must have altered relationships between patrilines in even the egalitarian TibetoBurmese villages, ${ }^{10}$ perhaps in ways similar to those that changed foraging strategies and land tenure relationships in the North American fur trade (Wolf, 1982). The ability of the Nepali state to intervene in local productive

${ }^{10}$ See, for example, Panter-Brick's characterization of the Tamang of Salme in this volume. Also see Chapters 2 and 3 of Holmberg's recent study (1989). 
strategies has been longstanding as indicated by the calls for corvée labor from even remote villages in the central Nepal Himalaya (Regmi, 1978; Holmberg, 1989). Similarly, evidence that land pressure and differential access to land resources existed from an early date within local settings is indicated by the many petitions to defend land grants collected in the Regmi Research Series. ${ }^{11}$

In Phalabang, Zurick demonstrates that proto-state interactions with local populations have been important in the Himalaya even before the eighteenth and nineteenth century development of the modern Nepali state. He shows, moreover, that the settlement patterns characterizing the area are a product of successive waves of different ethnic migration conditioned by the land tenure relationships between subordinant and dominant groups. Importantly, the expansion of populations into new lands and the deforestation beginning in earnest in the last century are shown to have derived as much from state policy (Tucker, 1983) as from local pressure. To be sure, local population pressures contributed to the process, but the centralization of authority at the state level accelerated the land clearing at the behest of grantees from outside of the area. Zurick very nicely shows that an ahistorical approach to adaptation risks serious misinterpretation of local patterns. He also demonstrates that the comparatively scant historical documentation for Himalayan communities nevertheless permits plausible reconstruction at a level that can inform our understanding of current processes. ${ }^{12}$

Finally, Pradyumna Karan reminds us that the detailed study of adaptation has important practical consequences and brings us back to the development literature which has motivated much of the research in the Himalaya (for example, Mahat, Griffin, and Sheperd, 1986; Fox, 1987; Bajracharya, 1983a, 1983b). Karan's is also the only contribution in this special issue to deal with a Himalayan setting other than Nepal, and emphasizes the extent to which our picture of human adaptations to the Himalaya

\footnotetext{
${ }^{11}$ Many of these land grant petitions were initiated by lamas at gompas established with the understanding that large tracts of land would be designated for the use of the lamas and closed to agriculture, hunting, and gathering. They date from throughout the nineteenth century, with the earliest for which I have a date going back to 1793. The Regmi Research Series translates a range of documents relating to the centralization of state authority and its consequences for mountain communities. Typical decrees relate to corvée labor requirements such as in a document dating from 1830: "The inhabitants of Panchsayakhola in Nuwakot were ordered to provide Jhara labor services for the construction of a road along the Trishuli River under the supervision of Kaji Birakeshor Pande. People who were under obligation to work at the gunpowder factory were exempted" (Regmi, 1975, p. 113).

${ }_{12}$ One of the most promising new developments in community studies in the Himalaya is the creative use of what historical documents exist. Not all of these studies originated within an adaptive framework although they stand as powerful representatives of analyses that can incorporate process (Ortner, 1989; Holmberg, 1989; Mikesell, 1988).
} 
has depended on a single subregion. ${ }^{13}$ Karan underscores the urgency that motivates our study of Himalayan adaptations. He demonstrates that these environments are threatened by a complex array of processes including those internal to indigenous populations as well as to newly-developed patterns of use that come with intensive mining and the development of tourism. The solutions to these problems demand sensitivity to the special needs of the Himalayan peoples themselves as they continue to confront the problems of fulfilling their subsistence needs within their mountain habitats.

Macfarlane in 1976 noted the failure of anthropologists to confront the issue of social change in the Himalaya and elsewhere and suggested that the prime cause of social change was population growth (1976, p. 5; Poffenberger, 1980). Three of the contributions to this special issue ratify this crucial point: the central fact of adaptation in the Himalayan setting is that it is changing, and indeed has rarely been in stasis in historical times. ${ }^{14}$ Zurick pays attention to the historical depth and political contexts of these changes in one locality. Bishop shows the current context of change in the contours of village pastoralism. Karan places the consideration of change within a discussion of environmental degradation. The range of studies that have followed up Macfarlane's focus on demography, from aggregate level studies of population dynamics (Banister and Thapa, 1981) to more fine-grained studies focusing on special issues within demography (Karki, 1984, Nag, White, and Peet, 1978; Ross, 1984), have made it clear that population processes are themselves highly variable and integrated with the same social organizational, environmental, and political relationships that structure other aspects of human adaptation.

Past developments in Himalayan human ecology together with the studies collected here call for the theoretical and methodological sophistication appropriate to relating individual behavior to the whole range of contextual levels, historical, political, social organizational, and household, within which it occurs (Orlove, 1980; Orlove and Guillet, 1985). The past orientation of adaptive studies in the Himalaya toward specific empirical issues unmotivated by a larger theory of adaptation has been problematic. The strong point of these studies has been in the increasing refinement of detail concerning particular processes, such as the demographic (Macfarlane, 1976;

${ }^{13}$ This a point which Bharati (1988) makes and a problem which I confess I am reinforcing in my discussion here. Our reliance on Nepal for most of what we know of adaptation in the Himalaya, in fact, represents an important reversal of the situation as it existed in the last century (the Hodgson quote at the head of this essay). The reasons have to do, in part, with the restrictions imposed on foreign research in the sensitive border regions of India, but the issue is more complex and deserves treatment in its own right.

${ }^{14}$ Even the processes of monetization that play so large in the transformation of Himalayan economies in the 1980 s have a long history of affecting relationships within communities and households (Hitchcock, 1963). 
Fricke, 1986), or the relationships between a limited set of domains, such as ethnicity, environment, and economy (Fisher, 1986; Caplan, 1970). These issue-oriented studies have been weaker, however, in linking individual strategic variation to historical relationships between locally-relevant groups within villages, political relationships between communities, and the processes of state development in the Himalaya. Paradoxically, the one study from this region that makes an attempt to do so (Levine, 1988) is phrased as a critique of various adaptive models. Even this impressively textured study is, however, limited by the inability to link variations in demographic, economic, and other processes at the individual level for the entire community. Similarly, the multidisciplinary effort in Salme (Dobremez, 1986), of which the Panter-Brick contribution to this special issue is a small part, resulted in rich data within domains but has not yet taken advantage of that richness to analyze individual level variation in the context of social change.

The articles in this special issue of Human Ecology demonstrate some of the directions that studies of Himalayan adaptation need to go to continue filling out the picture that Hodgson found so obscure 150 years ago. The next breakthrough in studies of Himalayan adaptation will combine the detailed attention given to the use of zones exemplified by Metz's work together with an awareness of the historical contingencies of contemporary patterns as Zurick shows. Second, it will focus on economies organized at the household level, but will consider individuals in terms of their relationship with other household members and in terms of their life course positions as exemplified by the Bishop and Panter-Brick contributions. Karan's work illustrates the practical consequences of such work.

\section{REFERENCES}

Acharya, M. and Bennett, L. (1981). The Rural Women of Nepal: An Aggregate Analysis and Summary of 8 Village Studies. Center for Economic Development and Administration, Tribhuvan University, Kathmandu.

Alirol, P. (1976). Animal husbandry in the Ganesh Himal region: An essay in ecological synthesis. Contributions to Nepalese Studies 3(1): 47-61.

Allan, N. J. R. (1986). Accessibility and altitudinal zonation models of mountains. Mountain Research and Development 6(3): 185-194.

Andress, J. M. (1966). Culture and Habitat in the Central Himalayas. Unpublished Ph.D. dissertation in Geography, University of California, Berkeley.

Bajracharya, D. (1983a). Fuel, food, or forest? Dilemmas in a Nepali village. World Development 11(12): 1057-1074.

Bajracharya, D. (1983b). Deforestation in the food/fuel context: Historical and political perspectives from Nepal. Mountain Research and Development 3(3): 227-240.

Banister, J. and Thapa, S. (1981). The Population Dynamics of Nepal. Papers of the EastWest Population Institute No. 78. East-West Population Institute, Honolulu. 
Barth, F. (1956). Ecological relationships of ethnic groups in Swat, Northern Pakistan. American Anthropologist 58: 1079-1089.

Berreman, G. D. (1972). Hindus of the Himalayas: Ethnography and Change. University of California Press, Berkeley.

Bharati, A. (1988). Mountain people and monastics in Kumaon Himalaya, India. In Allan, N. J. R., Knapp, G. W., and Stadel, C. (eds.), Human Impact on Mountains. Rowman and Littlefield, Totowa, N.J. pp. 83-95.

Bista, D. B. (1967). People of Nepal. Ratna Pustak Bhandar, Kathmandu.

Brush, S. B. (1976). Cultural adaptations to mountain ecosystems, introduction. Human Ecology 4(2): 125-133.

Caldwell, J. C. (1982). Theory of Fertility Decline. Academic Press, New York.

Calkins, P. H. (1981). Silent slopes: Environmental economics for the Nepalese hills. Human Ecology 9(4): 495-501.

Caplan, L. (1970). Land and Social Change in East Nepal: A Study in Hindu-Tribal Relations. University of California Press, Berkeley.

Dahal, D. R. (1983). Poverty or Plenty: Innovative Responses to Population Pressure in an Eastern Nepalese Hill Community. Ph.D. dissertation in Anthropology, University of Hawaii, Manoa.

Dahal, D. R., Manzardo, A., and Rai, N. K. (1977). Land and Migration in Far Western Nepal. Center for Nepal and Asian Studies, Tribhuvan University, Kathmandu.

Dobremez, J.-F. (1986). Les Collines du Népal Central: Ecosystèmes, Structures Sociales et Systèmes Agraires. Institute National de la Recherche Agronomique, Paris.

English, R. (1985). Himalayan state formation and the impact of British rule in the nineteenth century. Mountain Research and Development 5(1): 61-78.

Fisher, J. F. (1985). The historical development of Himalayan anthropology. Mountain Research and Development 5(1): 99-111.

Fisher, J. F. (1986). Trans-Himalayan Traders: Economy, Society, and Culture in Northwest Nepal. University of California Press, Berkeley.

Fox, J. M. (1987). Livestock ownership patterns in a Nepali village. Mountain Research and Development 7(2): 169-172.

Fricke, T. (1986). Himalayan Households: Tamang Demography and Domestic Processes. Studies in Cultural Anthropology No. 11, UMI Research Press, Ann Arbor.

Fricke, T and Thornton, A. (1989). Family, Economy, and Changing Life Course Transitions: Evidence from the Agriculture to Wage Labor Transition in Nepal. Paper presented at the Population Association of America Meetings, Baltimore.

Fürer-Haimendorf, C. von (1964). The Sherpas of Nepal: Buddhist Highlanders. John Murray, London.

Goldstein, M. C. (1976). Fraternal polyandry and fertility in a high Himalayan valley in Northwest Nepal. Human Ecology 4(2): 223-233.

Goldstein, M. C. (1977). Population, social structure and strategic behavior: An essay on polyandry, fertility and change in Limi Panchayat. Contributions to Nepalese Studies 4(2): 49-62.

Goldstein, M. and Beall, C. (1981). Modernization and aging in the third and fourth world: Views from the rural hinterland in Nepal. Human Organization 40(1): 48-55.

Goldstein, M., Schuler, S., and Ross, J. L. (1983). Social and economic forces affecting intergenerational relations in extended families in a third world country: A cautionary tale from South Asia. Journal of Gerontology 38(6): 716-724.

Gorer, G. (1938). Himalayan Village: An Account of the Lepchas of Sikkim. Thomas Nelson and Sons, London.

Guillet, D. (1983). Toward a cultural ecology of mountains: The Central Andes and the Himalayas compared. Current Anthropology 24(5): 561-574.

Hagen, T. (1961). Nepal: The Kingdom in the Himalayas. Kummerly and Frey, Berne.

Hitchcock, J. T. (1963). Some effects of recent change in rural Nepal. Human Organization 22(1): $75-82$.

Hitchcock, J. T. (1966). The Magars of Banyan Hill. Holt, Rinehart, and Winston, New York. 
Hitchcock, J. T. (1973). Ecologically Related Differences Between Communities in West Central Nepal. Paper presented at the American Anthropology Association meetings, New Orleans.

Hitchcock, J. T. (1977). Buying time: Population, trees, Liebig's "law," and two Himalayan adaptive strategies. In Himalaya: Ecologie-Ethnologie. Centre National de la Recherche Scientifique, Paris.

Hitchcock, J. T. (1980). A Mountain Village in Nepal. Holt, Rinehart, and Winston, New York.

Hodgson, B. (1874). Essays on the Languages, Literature, and Religion of Nepal and Tibet Together with Further Papers on the Geography, Ethnology, and Commerce of those Countries. Trubner and Company, London (original 1849).

Hoffpauir, R. (1978). Subsistence strategy and its ecological consequences in the Nepal Himalaya. Anthropos 73(1-2): 215-252.

Holmberg, D. H. (1989). Order in Paradox: Myth, Ritual, and Exchange among Nepal's Tamang. Cornell University Press, Ithaca.

Karki, Y. B. (1984). Family type and fertility in rural Nepal. Contributions to Nepalese Studies 11(3): 47-61.

Levine, N. E. (1981). Law, labor, and the economic vulnerability of women in Nyinba society. Kailash: A Journal of Himalayan Studies 8(3-4): 123-153.

Levine, N. E. (1988). The Dyanamics of Polyandry: Kinship, Domesticity, and Population on the Tibetan Border. University of Chicago Press, Chicago.

Macfarlane, A. (1976). Resources and Population: A Study of the Gurungs of Nepal. Cambridge University Press, Cambridge.

Madan, T. N. (1965). Family and Kinship: A Study of the Pandits of Rural Kashmir. Asia Publishing House, New York.

Mahat, T. B. S., Griffin, D. M., and Shepherd, K. R. (1986). Human impact on some forests of the middle hills of Nepal 1. Forestry in the context of the traditional resources of the state. Mountain Research and Development 6(3): 223-232.

March, K. S., and Taqqu, R. L. (1986). Women's Informal Associations in Developing Countries. Westview Press, Boulder.

McDougal, C. (1968). Village and Household Economy in Far Western Nepal. Tribhuvan University Press, Kathmandu.

Messerschmidt, D. A. (1974). Gurung shepherds of Lamjung Himal. Objets et Mondes 14(4): 307-316.

Messerschmidt, D. A. (1976). Ecological change and adaptation among the Gurungs of the Nepal Himalaya. Human Ecology 4(2): 167-185.

Mikesell, S. L. (1988). The cotton road: Commodity penetration and the subjection of labor to the global economy in the shadow of empire. Unpublished Ph.D. dissertation in Anthropology, University of Wisconsin, Madison.

Molnar, A. (1981). The Kham Magar Women of Thabang. Center for Economic Development and Administration, Tribhuvan University, Kathmandu.

Nag, M., White, B., and Peet, R. C. (1978). An anthropological approach to the study of the economic value of children in Java and Nepal. Current Anthropology 19(2): 292-306.

Netting, R. McC. (1981). Balancing on an Alp: Ecological Change and Continuity in a Swiss Mountain Community. Cambridge University Press, Cambridge.

Nitzberg, F. L. (1970). Land, Labor, and Status: The Social Implications of Ecologic Adaptations in a Region of the Western Himalayas of India. Unpublished Ph.D. dissertation, Harvard University.

Orlove, B. (1980). Ecological anthropology. Annual Review of Anthropology 9: 235-273.

Orlove, B., and Guillet, D. (1985). Theoretical and methodological considerations on the study of mountain peoples: Reflections on the idea of subsistence type and the role of history in human ecology. Mountain Research and Development 5(1): 3-18.

Ortner, S. B. (1978). Sherpas Through Their Rituals. Cambridge University Press, Cambridge.

Ortner, S. B. (1989). High Religion: A Cultural and Political History of Sherpa Buddhism. Princeton University Press, Princeton.

Pant, S. D. (1935). The Social Economy of the Himalayans. Allen and Unwin, London.

Parry, J. P. (1979). Caste and Kinship in Kangra. Routledge and Kegan Paul, London. 
Peattie, R. (1936). Mountain Geography: A Critique and Field Study. Harvard University Press, Cambridge.

Poffenberger, M. (1980). Patterns of Change in the Nepal Himalaya. Macmillan, Delhi.

Regmi, M. C. (1975). Jhara labor services. Regmi Research Series 7(6): 113.

Regmi, M. C. (1978). Thatched Huts and Stucco Palaces: Peasants and Landlords in 19th Century Nepal. Vikas Publishing House, New Delhi.

Rhoades, R. E., and Thompson, S. I. (1975). Adaptive strategies in alpine environments: Beyond ecological particularism. American Ethnologist 2(2): 535-551.

Ross, J. L. (1984). Culture and fertility in the Nepal Himalayas: A test of a hypothesis. Human Ecology 12(2): 163-181.

Sacherer, J. (1977). The Sherpas of Rowaling: A hundred years of economic change. In Himalaya: Ecologie-Ethnologie. Centre National de la Recherche Scientifique, Paris, pp. 289-293.

Sharma, U. (1980). Women, Work, and Property in North-West India. Tavistock, London.

Toffin, G. (1976). The phenomenon of migration in a Himalayan valley in central Nepal. In Mountain Environment and Development. Swiss Association for Technical Assistance in Nepal, Kathmandu.

Tucker, R. (1983). The British colonial system and the forests of the western Himalaya, 1815-1914. In Tucker, R., and Richards, J. F. (eds.), Global Deforestation and the 19th Century World Economy. Duke University Press, Durham.

Wolf, E. (1982). Europe and the People Without History. University of California Press, Berkeley. 